\title{
Productivity Improvement through Creative Approach to Preventive Maintenance Method of Etch Process
}

\author{
Etch Process Preventive Maintenance방법의 창의적 \\ 접근방법을 통한 생산성 향상 \\ Hong Kyun Shim ${ }^{1}$, Yong Won Song ${ }^{2}$ \\ 심홍균 ${ }^{1}$, 송용원 ${ }^{2}$ \\ ${ }^{1}$ Engineer, SK Hynix Semiconductor Co., Ltd., 20, SK-ro, Heungdeok-gu,Cheongju-si, \\ Chungcheonbuk-do, Korea,hongkyun.shim@sk.com \\ ${ }^{2}$ Professor, Dept. Nano \& Semiconductor Engineering, Korea Polytechnic Univ., Sangidaehak-ro, \\ Siheung-si, Gyeonggi-do, Korea, ywsong@kpu.ac.kr
}

Corresponding author: Yong Won Song

\begin{abstract}
The era of the Fourth Industrial Revolution began as artificial intelligence and many technologies were automated. big data related industries are growing, and the semiconductor industry is also undergoing explosive demand and breakthrough development. Companies that have not overcome the challenges of growing technology limits, sophistication, yield, production rate, production volume, etc. have disappeared into history as they have been eliminated in the semiconductor ecosystem. Even now, there is fierce competition for survival. In the paper, we studied ways to reduce preventative maintenance (PM) time to improve product production and production speed. Fixed limits that are no longer solved by the existing improvement methods were grasped, and in the problem-solving methodology, they were solved using TRIZ, which specializes in solving difficult problems for which there is no current method. TRIZ's strong problem-solving ability is a problem-solving theory that can solve problems with creative ideas when applied to stereotyped problems that the present is the best. Its utility was proved by applying it to the actual field and solving many problems.
\end{abstract}

Keywords: FOS, PM, ETCH, TRIZ

요약: 인공지능과 많은 기술 부분이 자동화로 이루어지면서 4차 산업 혁명의 시대가 열렸다. Big Data 관련 산업이 성장하면서 반도체 산업 역시 폭발적인 수요와 함께 비약적 발전이 진행 중이다. 이러한 성장 속에 기술의 한계, 고도화, 수율, 생산속도, 생산량 등의 난제를 극복하지 못한 기업들은 반도체 생태계에서 도태되어 역사의 뒤안길로 사라져 왔으며, 현재에도 생존을 위한 초 단위 경쟁을 하고 있다. 본 논문에서는 제품의 생산량과 생산속도를 향상하기 위한 예방 정비 (Preventive Maintenance, PM) 시간을 줄이기 위한 방법들을 연구하였다. 기존에 사용하는 개선 방법으로는 해결이 되지 않는 고착된 한계점 한계점에 도달하여, 문제해결 방법론 중 현재의 방식들이 아닌 난제 해결에 특화된 트리즈를 이용하여 해결하고자 하였다. 현재의 방법에 적응하여 개선점이 보이지 않는 고정관념에 사로잡힌

Received: December 07, 2020; $1^{\text {st }}$ Review Result: January 21, 2021; $2^{\text {nd }}$ Review Result: March 09, 2021 Accepted: April 30, 2021 
문제는 해결하기 매우 어렵다. 그러나 트리즈의 강력한 문제 해결 능력을 적용하면 이러한 문제도 창의적인 아이디어로 문제를 해결할 수 있다. 본 사례 또한 트리즈를 적용하여 문제를 해결하였다.

핵심어: 특허검색, 예방 정비, 식각, 트리즈

\section{1. 서론}

현대사회는 모든 기술이 고도화되고, 크기는 작아지는 시대이다. 그중 반도체 산업은 $20 \mathrm{~nm}$ 를 넘어선 $10 \mathrm{~nm}$ 의 선 폭을 가진 반도체를 양산한다. 기술 발전에 따라 선 폭의 감소 화는 한계에 부딪혔으며, 이제는 $2 \mathrm{D}$ 메모리가 아닌 $3 \mathrm{D}$ 메모리의 반도체 적층 화의 시대로 발전 중이다[1]. 이러한 반도체의 제조는 크게 웨이퍼(Wafer) 제조, 산화, 포토, 식각, 증착 및 이온 주입, 금속 배선, 웨이퍼 자동 선별(Electrical Die Sorting), 패키징(Packaging) 등 크게 8대 공정으로 나뉘며 세부적으로 몇백 가지의 공정을 거치면서 생산이 된다[2]. 이처럼 기술적인 집약도는 높아지며, 진행하는 공정은 늘어나고 길어지며, 최고의 품질의 반도체를 대량 생산하는 형태의 산업으로 진행이 된다. 한정된 시간에 최고품질의 반도체의 대량 생산은 반도체 회사의 이익 창출과 밀접하게 관련이 되어있다. 그래서 생산성의 향상을 위해 다양한 접근을 시도하고 있지만, 기존의 생산성 향상 방식 틀에서 크게 벗어나지 못하는 한계에 직면하고 있다. 전통적인 방식의 고정관념에서 벗어나 새로운 방법으로 개선 활동을 하기 위해 창의적 문제 해결 이론인 트리즈를 도입하여 반도체 8대 공정 중 하나인 식각 공정의 장비 성능의 유지를 위하여 정기적인 세정 및 교체, 보수 등의 작업을 하는 일련의 행동인 예방 정비 작업에 적용해 보았다. 기존의 전통적인 예방 정비 과정은 장비를 순서대로 모두 분해하여 세정 및 수리 보수를 진행하느라 많은 시간을 소비하였다. 그러나 트리즈 문제 해결 방법의 표준해를 이용한 Trimming 기법을 이용하여 불필요한 작업 부분의 제거를 가능하게 개선하여 최소한의 예방 정비 진행 시간으로 생산 참여가 가능하도록 개선을 하고자 한다.

\section{1 식각 공정 및 FLEX DX}

식각 공정은 포토 공정에서 감광액(Photo register)을 도포한 후 노광 공정이 진행된 웨이퍼에 플라즈마(Plasma)를 이용해 도전체(Oxide Film)를 식각하는 공정이다. 식각이 진행된 곳은 통로가 생기며, 전기적 신호를 주고받을 수 있는 금속 전극을 코팅하는 공정이 진행된다[3]. (그림.1 참조) 공정 진행을 반복함으로써, 전기적 신호를 주고받을 수 있는 공간을 적층하여 $3 \mathrm{D}$ 메모리를 생산하게 된다. 그리고 식각 공정을 진행하는 장비의 종류는 다양하다. 다양한 회사의 장비 중 본 논문에서는 Lam Research 사의 FLEX DX 장비의 예방 정비 시간을 단축하는 연구를 진행하였다. 


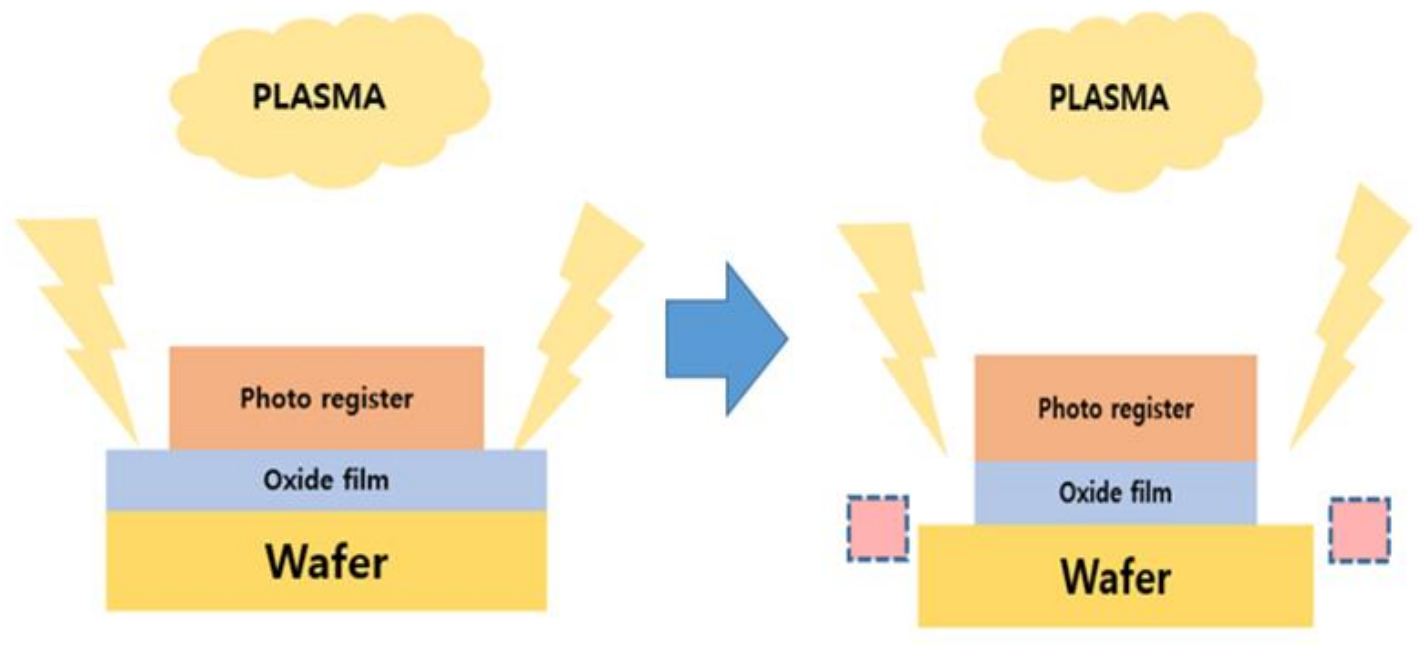

[그림 1] $\mathrm{ETCH}$ 공정 소개

[Fig. 1] ETCH Process Introduction

\subsection{TRIZ}

창의적 문제 해결 이론으로 알려진 트리즈(Theory of Inventive Problem Solving, TRIZ)는 러시아의 겐리히 알츠슐러(Genrich Altshuller)라는 발명가가 러시아 특허청에 등록된 약 150 만 건의 특허를 분석하여 수준에 따라 5단계로 나누고, 높은 3-5 수준의 문제를 어떻게 해결하였는지 분석하여 문제 해결의 공통 원리를 추출하여 만든 이론이다[4][5]. 트리즈는 문제 해결에 있어서 체계적인 접근 방법과 함께 문제 해결 방법을 과학적이며 논리적으로 도출하도록 도와주는 이론이다. 본 논문에서는 여러 TRIZ의 문제 분석 도구 중 기능 분석 및 인과 관계 분석을 이용하였으며, 문제 정의 및 해결을 위하여 모순 정립을 통한 40 가지 발명 원리, 분리 원리, 물질-장 문제 모델 및 표준해를 사용하였다. 그리고 기능 분석을 이용해 문제 해결 아이디어를 찾기 위해 특허 검색(Function Orient Search, FOS)를 활용하였다.

\section{2. 문제 분석}

\section{1 문제 상황}

반도체 생산 장비는 항상 일정한 조건을 유지해야만 고품질의 반도체 생산이 가능하다. 그러나 생산 장비의 특성상 항상 일정한 조건을 유지하기는 매우 어렵다. 특히 반도체의 제조 공정 중 식각 공정은 플라스마를 웨이퍼에 인가하여 식각 공정을 진행하는 공정으로 장비에 많은 영향을 끼친다. 플라스마가 웨이퍼에만 식각 작용을 하여야 하지만, 그 영향은 내부의 공정에 도움을 주는 부품들도 동반 식각을 발생시킨다. 그리고 동반되는 화학작용으로 인한 부산물도 함께 생성된다. 공정 부품이 식각 되고 부산물이 퇴적되면 Process Module(공정이 이루어지는 공간) 내부의 조건이 변화하게 되며, 이 변화의 정도에 따라 생산 품질에 영향을 미친다. 최고의 제품을 생산하기 위해 
생산에 영향이 발생하는 식각장비 내부의 예방 정비를 진행한다. 이 작업으로 인해 Process Module의 조건은 항상 최상으로 유지되며, 고품질의 반도체가 생산된다. 예방 정비 작업은 장비별 및 세부 공정별로 상이하나 평균적으로 장비별 월 약 1 2회를 진행하며, 1 회 진행 시 약 30 240분의 작업 시간이 소요된다. 이 작업이 진행되는 중에는 반도체 생산이 중지되기 때문에 비가동율이 늘어나게 된다. 예방 정비 작업을 얼마나 빠르고 정확하게 완료하는가에 따라서 반도체 생산량에 영향을 미친다. 그림.2를 참조하면 24시간 중 생산에 참여하지 못하는 시간의 비율인 비가동율은 전체 시간 대비 $13 \%$ 이며, 예방 정비는 이러한 $13 \%$ 의 비가동율 중 $48 \%$ 를 예방 정비가 차지하고 있다. 생산성을 개선하기 위하여 비가동율의 가장 큰 비중을 가진 예방 정비의 비중을 저감할 수 있는 방안이 필요하다. 본 논문에서는 이를 정확하고 신속하게 완료하는 것에 대한 방법을 강구하고자 한다.

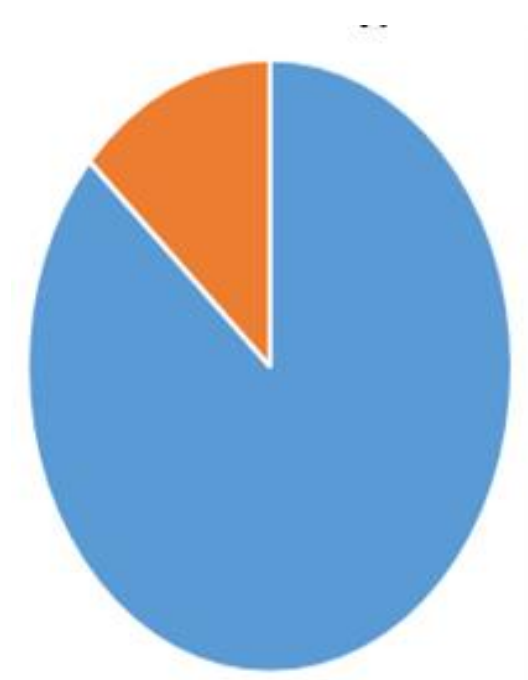

- operating rate $=$ Non-operation rate

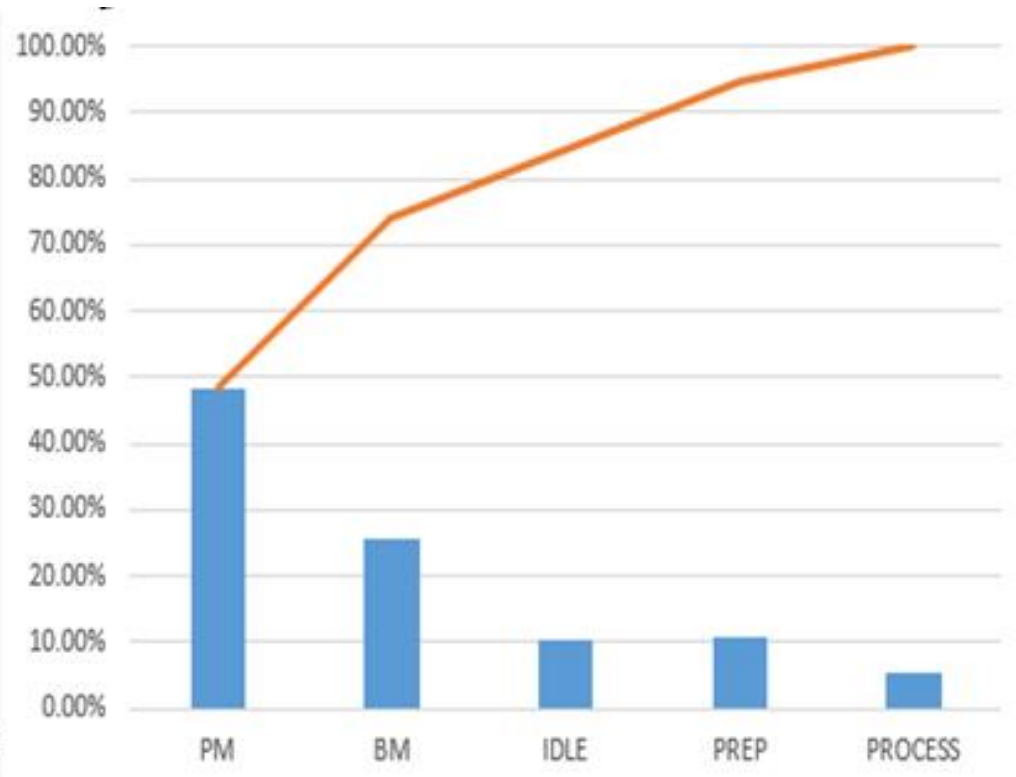

[그림 2] 장비가동율(2020.03)

[Fig. 2] Operating Ratio(2020.03)

\section{2 규제 및 제한조건}

예방 정비 작업의 정확하고 신속한 진행이라는 문제 해결에 있어 적절한 작업 방법의 변경이 필요하다. 그러나 변경이 불가한 규제 및 제한 조건은 항상 있으며, 이를 준수하여야 한다. 공정의 특수성 및 포함된 내 외부 자원의 특성으로 인한 변경이 가능한 혹은 변경이 불가능한 규제 및 제한 조건은 다음과 같다[표 1].

[표 1] 규제 및 제한조건

[Table 1] Regulations and Restrictions in Solving the Fume Retention Problem

제한 조건

(1) 간소화는 할 수 있으나, Process Module 조건의 원상복구

(2) 내부 부품의 장착 유무, 모양 및 재질 변경 불가 


\begin{tabular}{|c|c|}
\hline & (3) 내부 부품의 장착 압력 변경 불가 \\
\hline & (4) 공정 진행 제조 방법의 변경 불가 \\
\hline & (1) 세정 및 교체 부품의 수 \\
\hline ני & (2) 사용 가능한 세정 약품 사용 \\
\hline & (3) 세정 순서 및 방법의 변경 \\
\hline & (4) 세정을 진행하는 사람의 수 \\
\hline
\end{tabular}

\section{3 현재까지 실시한 방법}

예방 정비 시간의 개선을 위해 현재까지 제조사의 추천 방법, 설명서에 의거한 방법, 노하우에 의한 방법 등을 이용하였다. 제조사의 추천 방법은 현재도 사용을 하는 방법이며, 작업 진행 시간의 개선은 없으나, 조건의 복구는 확실한 장점이 있다. 설명서에 의거한 Step by Step 방식 진행으로 실수가 없다는 장점이 있으나, 이 방법 또한 작업 시간의 개선은 없다. 개인의 노하우에 의한 방법은 상황에 맞는 작업의 진행으로 작업 시간의 개선은 뛰어나지만, 작업자에 따라 다양한 실수가 발생할 가능성이 있고 조건의 복구는 확실하지 않다. 현재까지 다양한 방법을 이용한 개선으로 예방 정비 시간이 개선되었다. 그러나 현재 더 이상의 개선이 이루어지지 못해 일정 시간을 단축한 이후 답보 상태가 되어 있다. 예방 정비를 하는 방법에 대해서는 많은 사람이 “원래 저렇게 하는 거야” “제품 문제 만들지 말고 그냥 시키는 대로 하자” 라는 고정관념을 가진 상태로 예방 정비의 방법에 대해서는 의문점을 가지지 않고 더 이상의 개선은 힘들다는 생각이 많다. 체계적인 문제 분석 및 해결 기법을 제공하는 트리즈를 사용해서 고정관념을 파괴하는 아주 강력한 해결방법이 필요한 이유이다.

\section{3. 트리즈를 사용한 문제 분석}

\subsection{System 기능 분석}

정확한 분석을 위하여 트리즈의 문제 분석 기법 중 System 기능 요소 분석을 통한 공정 구성도를 이용하여 분석을 진행하였다. System 구성요소의 기능을 파악함으로써, 더욱 정확하고 빠른 문제 지점의 분석이 가능한 기법이다. Process Module 내부(그림.3)의 System 구성요소에는 Ground Ring, Qt’z ring, Ceramic Ring, Ground cover Ring, Edge Ring, Electrostatic Chuck(ESC) 등이 있으며, 작업을 위한 공구, 반도체 생산의 기본이 되는 웨이퍼, 플라즈마 등이 있다.(그림.4) 구성요소의 기능은 표2와 같다. 각 구성요소의 기능을 결합하여 서로의 연관성을 따져보는 System 구성도(그림.5)를 이용한 분석을 하였다. 공정을 진행함에 따라, 플라즈마에 의한 내부 부품의 식각이 발생하며, 더불어 발생하는 화학작용으로 부산물이 발생한다. 이 부산물은 각 원소와 결합하여 고체 형상의 퇴적물이 생성된다. 이 두 가지 조건 모두 Process module 조건을 변화하게 하는 요소이다. 식각을 방지하기 위해 내부 부품의 재질을 플라즈마에 더 강한 물질로 변경을 하거나, 식각이 되지 않는 환경 조성이 필요하다. 그러나 내부 부품의 재질 변경과 
환경변화를 위한 공정 진행 제조법의 변경은 규제 및 제한 조건에 변경 불가에 해당하여 고려하지 않았다. 부산물에 의한 영향을 제어하고자, 규제 및 제한 조건에 해당하는 내용이 없는, 부산물의 제거를 신속하고 정확하게 하여 예방 정비 시간의 개선으로 진행하였다.

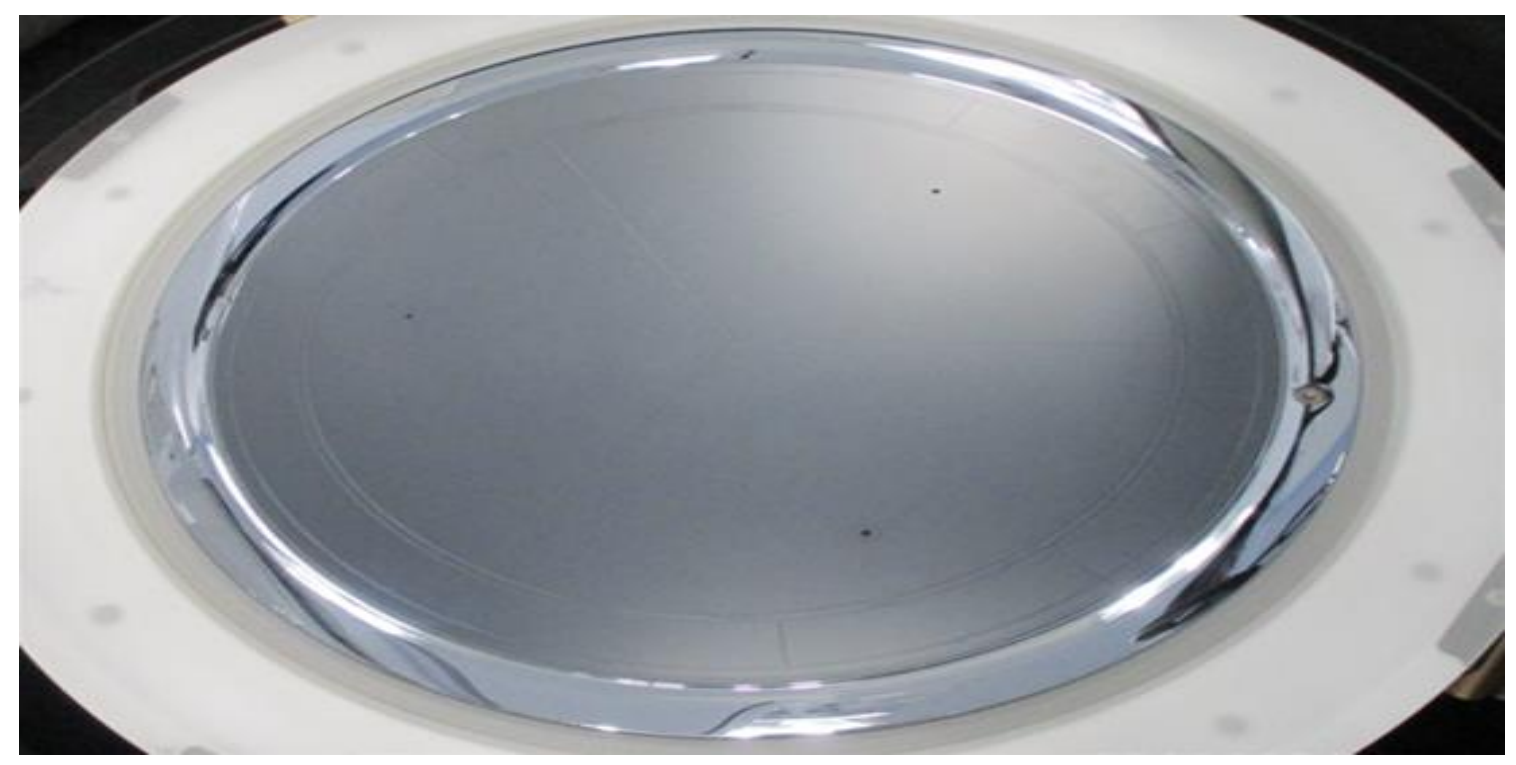

[그림 3] Process Module 내부

[Fig. 3] Inside the Process Module

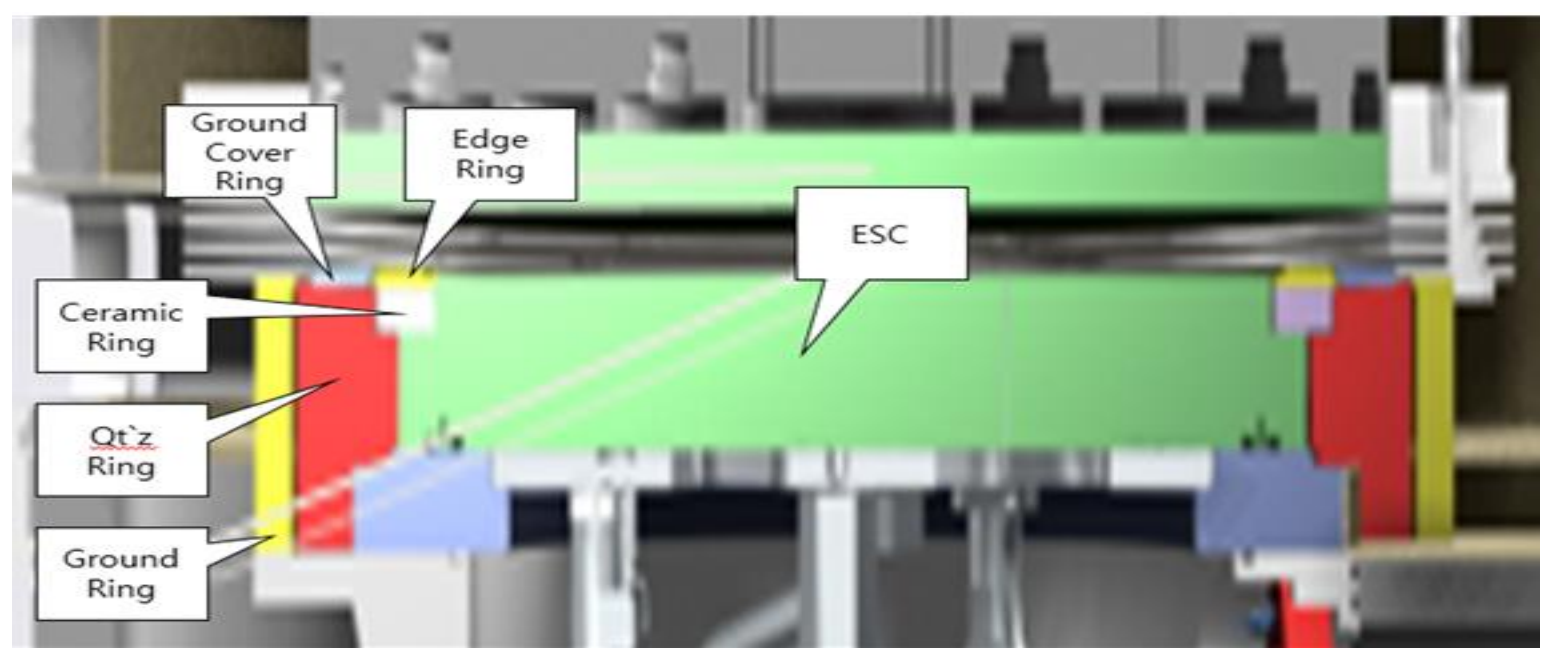

[그림 4] 내부 부품 구성도

[Fig, 4] Internal parts diagram

$$
\text { [표 2] 기능 요소 분석 }
$$

[Table 2] Functional Element Analysis 


\begin{tabular}{|c|c|}
\hline Edge ring & 웨이퍼에 플라즈마를 집중 \\
\hline Ground Ring & ESC와 Wall liner 사이의 전하를 공급 \\
\hline Wall liner & 플라즈마 및 부산물로부터 wall을 보호 \\
\hline Ground cover ring & 알루미늄 소재의 Ground ring을 보호 \\
\hline Qt'z ring & 플라즈마의 손실을 방지 \\
\hline Ceramic ring & 플라즈마로부터 Qt'z ring 및 ESC를 보호 \\
\hline ESC & 정전기를 이용하여 반도체 제조를 위한 웨이퍼를 고정 및 열화로부터 보호 \\
\hline Plasma & RF, Gas, Pressure를 이용하여 공정을 진행하기 위해 생성된 전기적 에너지 \\
\hline
\end{tabular}

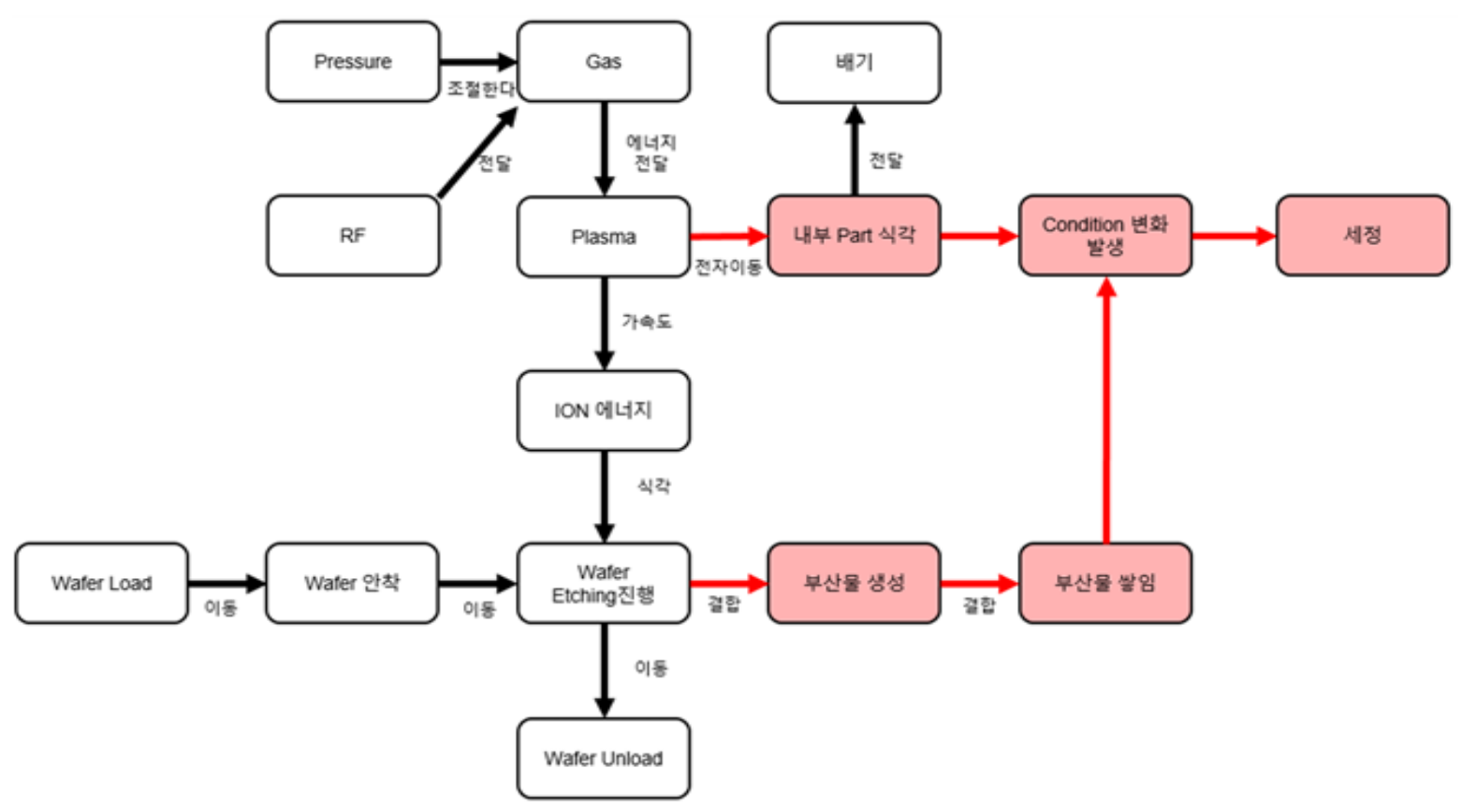

[그림 5] 공정 진행 구성도

[Fig. 5] Process Diagram

\section{2 부산물 제거}

\subsection{1 부산물의 퇴적}

부산물은 공정 진행에 있어서 필수적으로 발생하며 퇴적이 된다. 부산물은 전체 부품에 소량씩 고르게 분포를 하지만, 주로 $\mathrm{ESC}$ 의 옆면에 다량의 부산물 퇴적이 발생한다[그림 6]. $\mathrm{ESC}$ 는 공정 진행에 대단히 중요한 부품으로써, 퇴적물에 민감하게 반응하여 Process module의 조건 변화에 매우 심각한 영향을 끼친다. 예방 정비의 주요 과정은 부품 교체 및 $\mathrm{ESC}$ 옆면에 있는 다량의 부산물 제거라고 말할 수 있다. 부산물 
제거를 위해서는 내부 6종 부품을 탈착 -> 부산물 제거 -> 부품의 장착 순서로 진행이 되고 있다.

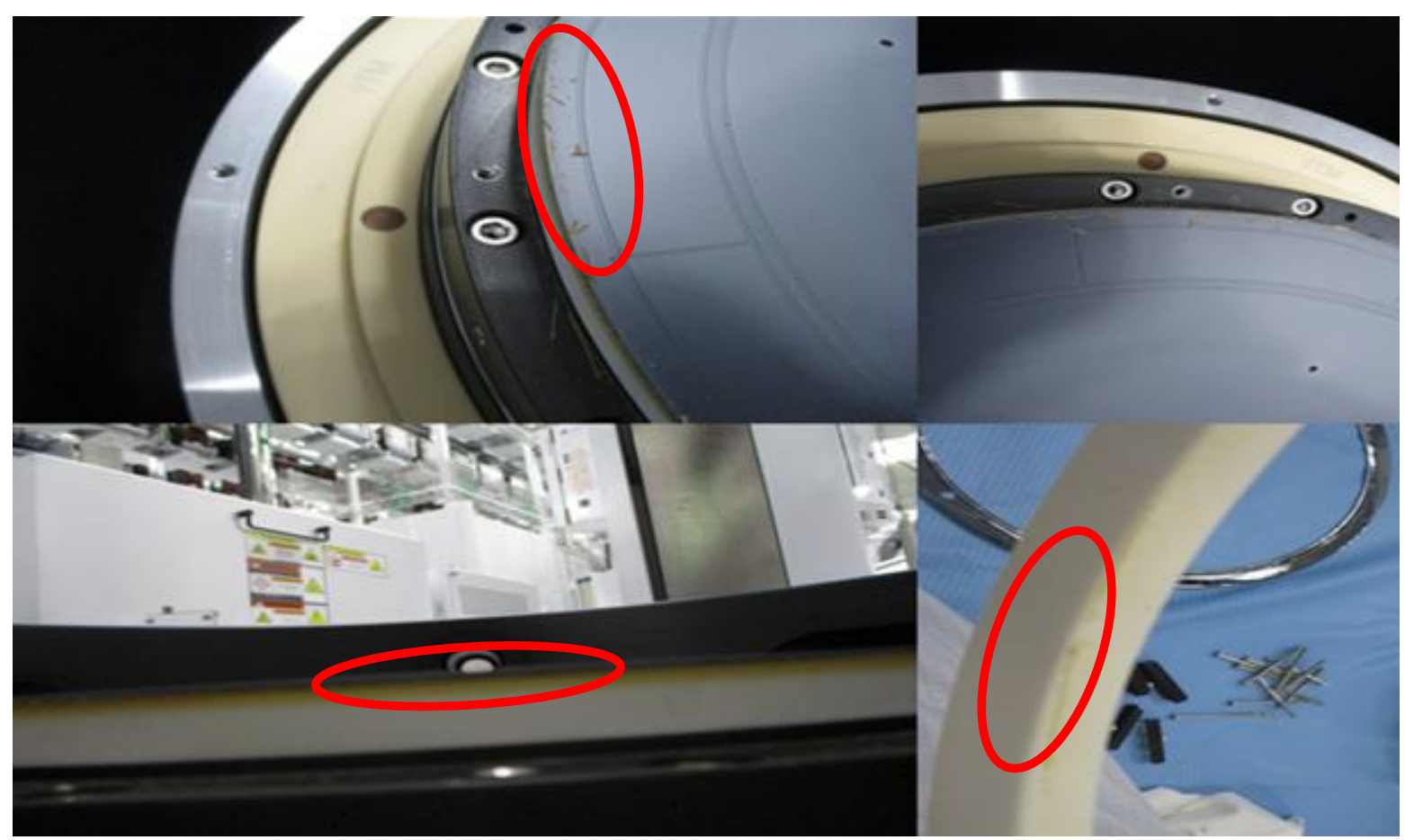

[그림 6] Process Module의 부산물

[Fig. 6] Process Module by-product

\subsection{2 인과관계 분석(Cause-effect chain analysis : CECA) 분석}

부산물 퇴적 과정을 세밀하게 분석하기 위해 트리즈 분석 도구인 인과관계 분석(Causeeffect chain analysis : CECA)을 실시하였다[그림 7]. 인과관계 분석은 여러 가지 원인이 있는 문제를 체계적으로 분석하는 방법이다. 인과 관계에 있어 유해한 작용이 발생하는 시간(Operation Time, OT)과 문제 발생 영역(Operation Zone, OZ)을 분석하여 문제 해결방법에 더욱 쉽고 정확하게 도달 할 수 있도록 도와준다[6][7]. 부품의 탈착 및 장착에 대해서 개선이 필요하므로, 장착과 탈착에 대해서 분석한다. 부품의 장착 및 탈착에서의 주된 목적은 $\mathrm{ESC}$ 옆면에 퇴적된 다량의 부산물 제거를 진행하기 위해서이며(OT), 이를 위해서 6종의 부품을 제거한다. 이 부위의 부산물 제거를 위해서는 ESC 바깥쪽의 Ceramic ring을 탈착하여야 한다.(OZ) Ceramic ring은 안쪽으로는 ESC 주위를 감싸고 있으며, 바깥쪽으로는 Qt’z ring이 감싸고 있다. 위로는 Edge Ring이 장착되며, Edge ring의 기능수행으로 인해 Ceramic ring은 구조적으로 Qt'z ring 내부에 얹혀있는 형태를 가진다. Ceramic ring의 구조적인 위치 및 고유의 모양으로 인하여 단독으로 탈착은 불가하다. 이러한 이유로 ESC Side 부위 세정을 하기 위한 6종 부품을 탈착하는 것이다. 또한 부품을 탈착하는 과정에서 부품 간의 마찰이 발생한다. 마찰이 발생하게 되면 소량의 부산물이 퇴적되어 있는 영향이 비교적 적은 부품의 부산물 역시 제거를 하여야 한다. 마찰로 발생하는 부산물을 최소화하기 위해서는 최소한의 부품 탈착이 필요하다. 
그림.7을 참조하여, ESC 옆면에 퇴적된 부산물을 제거하기 위해서 최소한으로 탈착되어야 하는 부품은 Ceramic Ring이다. 이 부품만의 탈착을 진행하여 부산물을 제거하는 것이 최소한의 시간을 소비하여 예방 정비를 진행하는 최고의 문제 해결 방법이다. Ceramic Ring만의 단독 탈부착을 진행이 가능한 방안이 필요하였다.

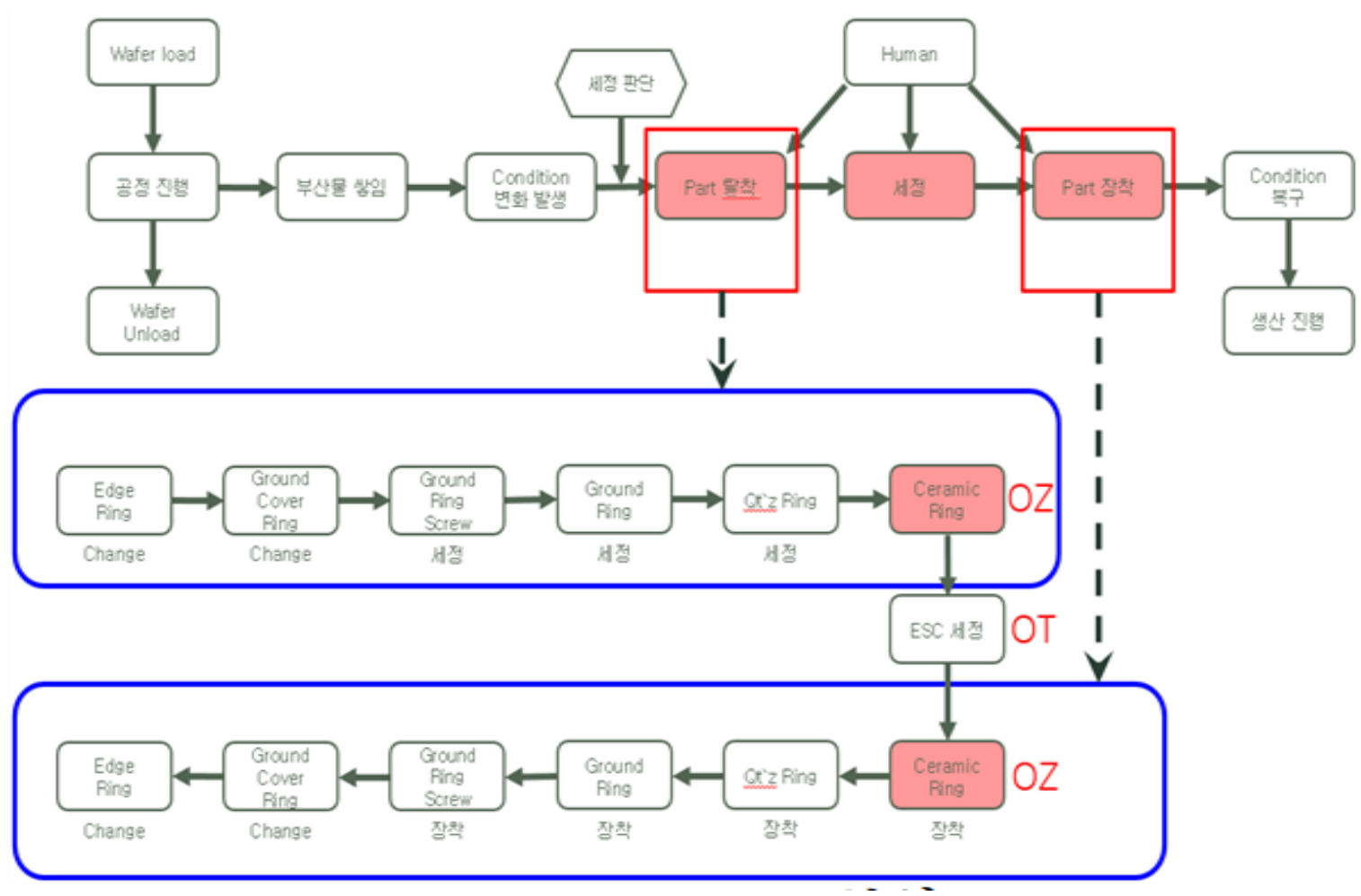

[그림 7] CECA 분석

[Fig. 7] CECA Analysis

\section{3 과제 정의}

문제를 분석하여 원인을 규명하고, 문제해결을 위해 구체적으로 해결해야 할 과제를 결정해야 한다. 문제가 발생함에 따라 어떠한 부분이 과거에 문제이며, 이후는 어떠한 부분의 개선으로 해결이 가능한 것인지 정의하였다. Ceramic ring의 단독 탈부착이 불가능하여 문제가 발생하는 것이었다. Process Module의 예방 정비 시 획일적인 6종 부품 탈착 및 장착을 통한 시간 지연이 발생한다. 이를 해결하기 위하여 문제가 발생하는 부분만의 부산물 제거를 하기 위하여 Ceramic Ring 단독 탈착을 가능하게 하여 예방 정비 시간을 단축할 수 있는 방법을 찾는 것으로 과제를 정의하였다[그림 8].

그동안 다양한 방법으로 문제를 분석하여 문제 해결을 시도했었다. Ceramic Ring을 탈착하지 않은 상태에서 보이는 부분만의 세정을 진행하였으나, 완벽한 부산물의 제거가 되지 않아 더 잦은 예방 정비가 필요하였다. Edge Ring과 $\mathrm{ESC}$ 사이의 틈새를 없애, 부산물의 원천적인 차단을 하려 하였으나, 공정 변화의 위험 및 약 $0.5 \mathrm{~mm}$ 의 좁은 틈새로 인하여 적용이 불가능하였다. 부산물이 주로 퇴적되는 ESC 옆면의 Coating을 
시도하였으나, 공정 변경 발생 우려로 인하여 시도하지 못하였다. 폭 $2 \mathrm{~cm}$ 및 $350 \mathrm{~g}$ 의 고유 성질로 인하여 Ceramic ring의 단독 탈착은 불가능하다는 고정관념으로 시도되지 못했다.
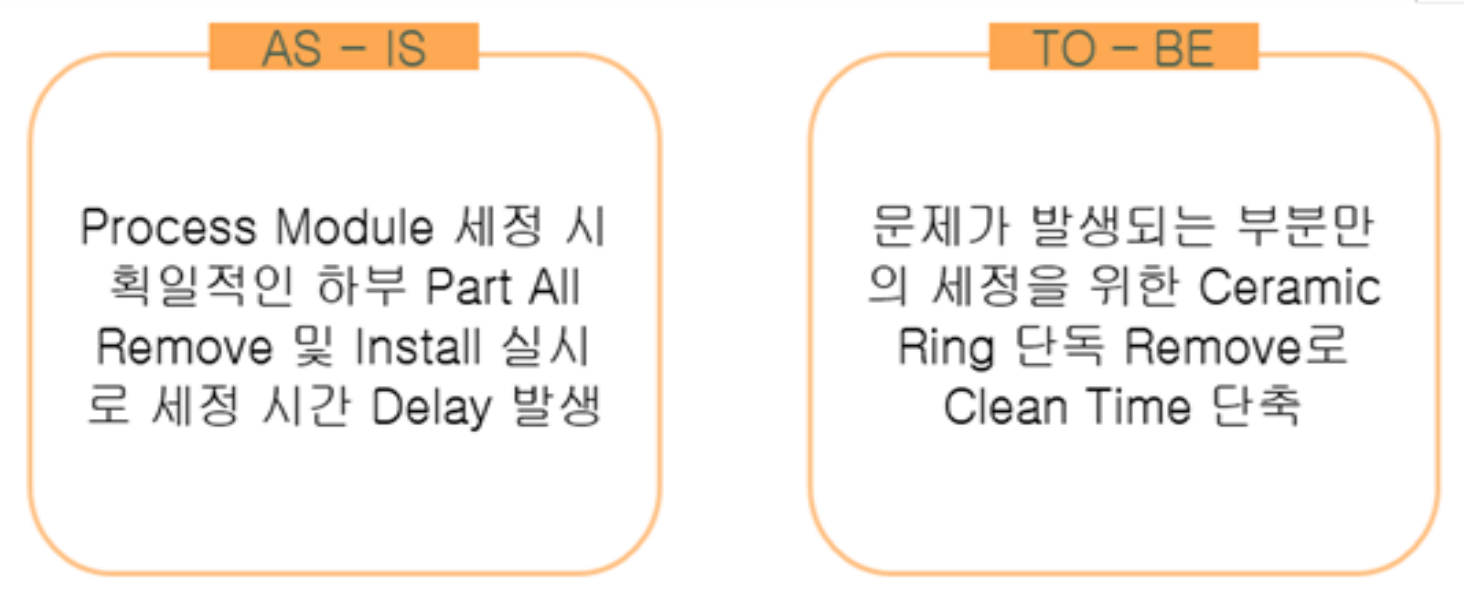

[그림 8] 과제 정의

[Fig. 8] Task Definition

\section{4. 문제 해결}

\section{1 이상적 해결안 제시 (IFR: Ideal Final Result)}

이상적 최종 결과(IFR)는 기존 시스템의 장점은 그대로 유지하면서 단점은 제거한 이상적 해결안을 의미한다. 각각의 기법을 적용하여 이상적인 해결안을 탐색한다[8].

\subsection{1 기술적 모순을 이용한 발명 원리}

기술적 모순이란 하나의 시스템에서 한 가지 특성을 개선했을 때 다른 특성이 나빠지거나 새로운 문제가 발생하는 어려운 문제를 의미한다[9]. 현 상황의 기술적 모순은 6종 부품의 탈 부탁으로 진행하는 예방 정비는 공정 변화 없이 안정적인 장비 운용이 가능하지만, 6종 부품의 탈부착으로 인한 예방 정비 시간이 길어져 생산량 및 가동율이 저하되는 문제이다. 예방 정비를 실시하는 기준은 안정적인 장비 운용을 위한 것이므로, 안정적인 장비 운용이 가능하면서 6종 부품 모두를 탈착하지 않고 최소한의 부품 탈부착을 진행하여 예방 정비 시간을 단축할 수 있는 방법을 찾아야 한다. 모순 행렬 표에 대입하여 세로축에 개선하려는 특성을, 가로축에는 악화되는 특성을 각각 대입하여 문제해결에 활용할 수 있는 발명 원리를 확인 할 수 있다. 개선하려는 특성은 모양이며, 이에 따른 악화되는 특성인 시간의 소비를 대입하여 통합/결합/병합 발명 원리를 이용한 Ceramic Ring 및 Edge Ring을 접합하여 일체형으로 제작한 아이디어를 얻을 수 있었고, 복제 / 대체수단 / 복사 발명 원리를 이용한 손잡이를 대체 할 수 있는 대체 매개 물질을 이용하여 Ceramic을 들어 올린다 등의 아이디어 얻을 수 있다. 
[표 3] 발명 원리를 이용한 아이디어

[Table 3] Ideas Using Inventive Principles

\begin{tabular}{|c|c|c|}
\hline & $\begin{array}{c}\text { 악화되는 특성 } \\
25 . \text { 시간의 소비 }\end{array}$ & 해결방법 \\
\hline \multirow{2}{*}{$\begin{array}{c}\text { 개선하려는 특성 12. } \\
\text { 모양 }\end{array}$} & 5. 통합 / 결합 / 병합 & $\begin{array}{c}\text { Ceramic ring과 Edge ring을 일체형으로 제작하여 } \\
\text { Edge Ring과 함께 들어올린다 }\end{array}$ \\
\cline { 2 - 3 } & 26. 복제 / 대체수단 / 복사 & 대체 매개물을 이용하여 Ceramic ring을 들어 올린다 \\
\hline
\end{tabular}

\subsection{2 물리적 모순을 이용한 분리 원리}

트리즈 핵심 개념인 물리적 모순을 통하여 문제 해결에 접근해 보았다. 물리적 모순은 문제가 발생하는 한 요소에서 서로 다른 물리적 상태가 요구되는 것이다[9]. 물리적 모순은 시간 / 공간 / 부분과 전체 분리의 원리로 문제해결 아이디어를 도출할 수 있다. 현 상태의 물리적 모순은 꾸준히 변화 없는 조건을 유지하고, 예방 정비 시간도 단축하기 위해 Ceramic ring은 단독 탈착을 위해 두께가 $\mathrm{ESC}$ 보다 두꺼워야 하고, 공정 진행에 영향이 없기 위해서는 $\mathrm{ESC}$ 보다 두께가 얇아야 한다. 물리적 모순의 해결방법인 분리의 원리를 이용하여 해결 아이디어를 찾아 보았다. 시간 / 공간 / 부분과 전체 분리 등 3 가지 분리 원리를 이용하여 해결 아이디어가 도출되었다.

[표 4] 분리 원리를 이용한 아이디어

[Table 4] Ideas Using Separation Principles

\begin{tabular}{|c|c|}
\hline 분리 원리 & 해결 방법 \\
\hline 시간 분리 & 제거 시에만 높이가 높아져 단독 탈착이 가능하도록 한다 \\
\hline 공간 분리 & $\begin{array}{c}\text { Ceramic ring의 높이를 변경 및 단차를 생성하여 단독 탈착이 가능하도록 } \\
\text { 한다. }\end{array}$ \\
\hline 부분과 전체 분리 & $\begin{array}{c}\text { Ceramic ring을 하부 일체형으로 제작하여 부분을 전체로 변경하여 단독 } \\
\text { 탈착이 가능하도록 한다. }\end{array}$ \\
\hline
\end{tabular}

\subsection{3 물질 장 분석을 이용한 표준해}

트리즈 이론에 따르면 어렵고 복잡한 문제는 대부분 모순을 가지고 있으며, 이 모순을 발명 원리와 분리 원리를 가지고 창의적으로 해결할 수 있다. 그러나 모순을 가지고 있지 않거나, 혹은 모순을 찾기 어려운 상황도 있다. 그때 사용하는 트리즈 문제 해결 방법은 물질-장 분석을 시행하고 표준해를 통해 문제를 해결하는 것이다. 물질-장 분석은 두 물질과 그사이에 작용하는 장(Field)을 분석하여 유익한 관계와 유해한 관계, 그리고 부족한 관계를 찾는 분석이다. 그리고 문제 형태에 따라 물질을 효과적으로 도입하여 해결안을 찾을 수 있는 체계적인 방법이다(표준해). 현재의 문제는 Ceramic ring의 단독 탈부착이 안 되는 것이다. 가상의 손잡이를 압축과 진공 에너지라는 장을 투입할 수 있다.

[표 5] 물질 장을 이용한 아이디어

[Table 5] Ideas Using Su-field 


\begin{tabular}{|c|c|}
\hline 물질 장 & 해결 방법 \\
\hline 압축 & $\begin{array}{c}\text { Ceramic ring에 새로운 압축 에너지를 이용해 손잡이를 생성하여, 단독 } \\
\text { 탈착이 가능하도록 한다. }\end{array}$ \\
\hline 진공 & $\begin{array}{c}\text { Ceramic ring에 새로운 진공 에너지를 이용해 손잡이를 생성하여, 단독 } \\
\text { 탈착이 가능하도록 한다. }\end{array}$ \\
\hline
\end{tabular}

물질-장 분석 및 표준해, 발명 원리를 활용하여 진공 흡착이라는 아이디어를 얻었으며, 진공 흡착을 위한 알맞은 공구를 선택하여야 한다. Ceramic ring의 좁은 표면에 사용할 수 있는 제품이 시중에서는 찾아볼 수가 없었다. 따라서 특허 검색 (Function Oriented Search, $\mathrm{FOS}$ [10]를 기반으로 특허 검색을 통해 진공 핀셋을 이용해 작은 물체를 들어 올리는 간편한 장비가 있음을 발견하였다.

\section{2 최종 해결안 도출}

도출된 아이디어를 종합하여, 최종 해결안 도출을 위한 평가를 진행하였다. 발명 원리, 표준해, 분리 원리를 이용하여 도출한 3 가지의 아이디어에 대한 평가를 진행하였다[그림 10]. 평가 결과 경제적이고 적용 가능성이 가장 좋은 진공 흡착기를 이용하여 Ceramic Ring을 들어 올리는 해결안이 채택되었다. 진공 흡착기를 이용하여 가상의 손잡이를 이용해 Ceramic Ring을 단독으로 탈착하여 예방 정비를 진행하면, 소비되는 시간은 30 분 $>15$ 분으로 $50 \%$ 감소하였다. 예방 정비 순서가 기존 12 단계에서 7 단계로 간소화되어 효율이 대폭 증가하였다.

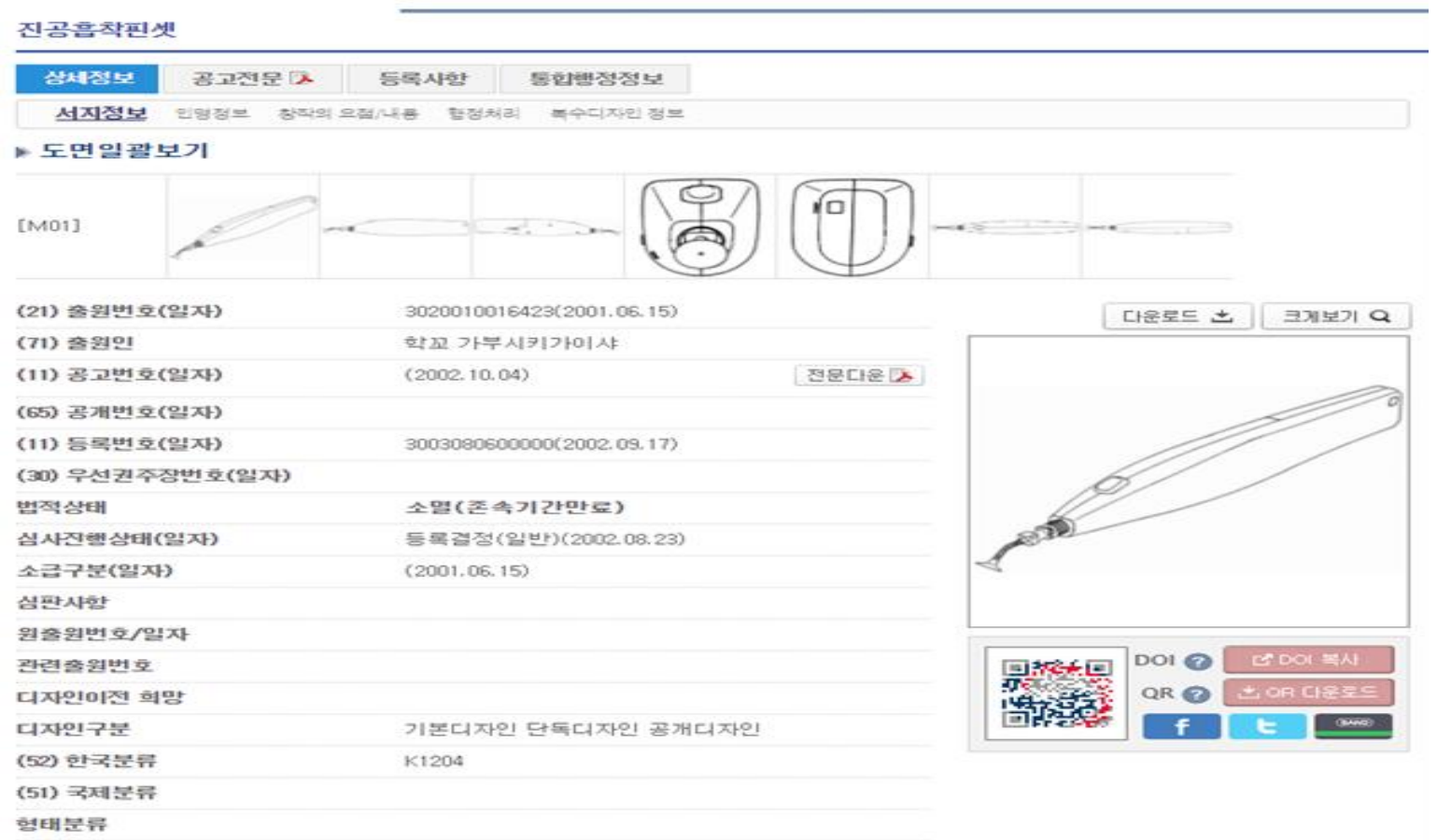

[그림 9] FOS를 이용한 특허 검색

[Fig. 9] Patent Search Using FOS 


\begin{tabular}{|c|c|c|}
\hline & 일반 용어로의 표현 & 39가지 일반화 파라미터로 표현 \\
\hline 개선하려는 특성 & 단독 탈착 & 모양 \\
\hline 악화 되는 특성 & 비간의 소비 & 공정 위험 \\
\hline 추천하는 발명 원리 & 복제 / 대체수단 / 복사 / 통합 / 결합 / 병합 \\
\hline
\end{tabular}

\begin{tabular}{|c|c|c|c|c|c|c|c|c|}
\hline \multirow{5}{*}{$\frac{\mathbb{d}}{0}$} & & \multirow{2}{*}{ 원리 } & \multirow{2}{*}{ 아이디어 내용 } & \multicolumn{5}{|c|}{ 아이디어 평가( $\bigcirc: 5, \bigcirc: 3, \Delta: 1)$} \\
\hline & & & & 이상성 & 모순 해 & 현실성 & 점수 & 순위 \\
\hline & 1 & $\begin{array}{l}\text { 대체수단 / 표 } \\
\text { 준해 }\end{array}$ & $\begin{array}{l}\text { 진공 핀셋을 이용하여 Ceramic Ring } \\
\text { 을 들어 올린다 }\end{array}$ & & 0 & 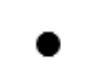 & 15 & 1 \\
\hline & 2 & $\begin{array}{l}\text { 통합 / 부분과 } \\
\text { 전체 분리 }\end{array}$ & $\begin{array}{l}\text { Ceramic Ring 과 Edge Ring을 일체 } \\
\text { 형으로 결합하여 함께 들어 올린다. }\end{array}$ & $\mathrm{O}$ & 0 & $\Delta$ & 9 & 2 \\
\hline & 3 & 공간 분리 & $\begin{array}{l}\text { Ceramic Ring의 높이를 변경하여 들 } \\
\text { 어 올린다 }\end{array}$ & 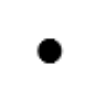 & $\Delta$ & $\Delta$ & 7 & 3 \\
\hline
\end{tabular}

[그림 10] 아이디어 평가표

[Fig. 10] Idea Evaluation Sheet

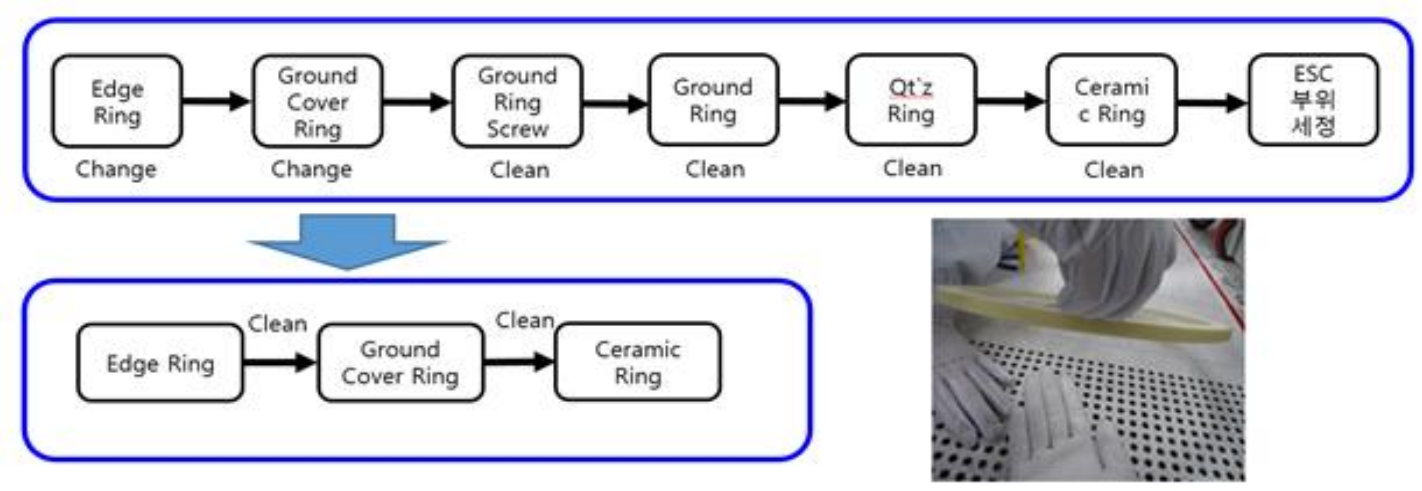

[그림 11] 예방 정비 순서

[Fig. 11] PM Order

\section{5. 해결안 평가}

이 해결안으로 예방 정비 시간의 감소에 따른 가동율이 향상이 되었다. 가동율 향상이 되어 생산성 역시 향상이 되었으며, 현재 폭넓게 현업에서 사용하고 있다. 본 사례에서 TRIZ 는 정확한 문제 분석이 가능하며, 이를 바탕으로 많은 아이디어를 제공하며 그 중 
최적의 해결안을 찾을 수 있다는 것이 확인되었다. 이처럼 트리즈의 강력한 문제 해결 능력은 현재가 최선이라고 생각하는 고정 관념적 문제에도 적용하면, 창의적인 아이디어와 함께 문제 해결을 이루어 낼 수 있는 문제 해결 이론이고 산업 현장에서 유용하게 활용할 수 있다.

\section{6. 감사의 글}

This research was supported by Basic Science Research Program through the National Research Foundation of Korea (NRF) funded by the Ministry of Education (2018R1D1A1B07049244).

\section{References}

[1] D. Y. Kim, Latest Semiconductor Process Technology, The Institute of Electronics and Information Engineers, (2015), Vol.42, No.1, pp.91-98.

[2] http://www.samsungsemiconstory.com/2206, Jan 16 (2020)

[3] http://www.samsungsemiconstory.com/1667, Jan 04 (2018)

[4] H.Y. Na, M.W. Song, Y. T. Park, On the Use of TRIZ Inventive Principles by Industries: Focusing on the Awarded Patents at the Korea Invention Patent Exhibition, Journal of Engineering Education Research, (2019), Vo.22, No.2, pp.28-35, http://dx.doi.org/10.18108/jeer.2019.22.2.28

[5] E. K. Kim, B. C, Koo, A Study of Applying TRIZ in Software Development, Journal of Information and Communication Convergence Engineering, (2014), Vol.18, No.3, pp.719-726, https://doi.org/10.6109/jkiice.2014.18.3.719

[6] Y. W. Song, K. M Kim, S. H Kim, Problem analysis and task definition, Creative Problem Solving Theory TRIZ, KSA Media, (2017)

[7] C. Dobrusskin, On the Identification of Contradictions Using Cause Effect Chain Analysis, Procedia CIRP, (2016), Vol.39, pp.221-224, https://doi.org/10.1016/j.procir.2016.01.192

[8] E. G. Kim, Inventive Problem Solving using IFR", Asia-pacific journal of Multimedia Services Convergent with Art, Humanities and Sociology, (2016), Vol.6, No.9, pp.473-481, http://dx.doi.org/10.14257/AJMAHS.2016.09.56

[9] J. S Hyun, C. J Park, Classification of Contradiction Relations and their Solving Dimensions based on the Butterfly Model for Contradiction Solving for Physical Contradiction of TRIZ, Knowledge Management Research, (2014), Vol.15, No.4, pp.15-34, https://doi.org/10.15813/kmr.2014.15.4.002

[10] S. S. Litvin, New TRIZ based tool - function-oriented Search, Paper presented at the 7th Annual Conference of the Altshuller Institute for TRIZ Studies, (2005), April 17-19; Detroit, USA. 